Discussion Paper No. 709

\title{
YARDSTICK COMPETITION TO ELICIT PRIVATE INFORMATION: AN EMPIRICAL ANALYSIS OF THE JAPANESE GAS DISTRIBUTION INDUSTRY
}

\author{
Ayako Suzuki
}

March 2008

The Institute of Social and Economic Research Osaka University

6-1 Mihogaoka, Ibaraki, Osaka 567-0047, Japan 


\title{
Yardstick Competition to Elicit Private Information: An Empirical Analysis of the Japanese Gas Distribution Industry ${ }^{\dagger}$
}

\author{
Ayako Suzuki ${ }^{\ddagger}$ \\ Institute of Social and Economic Research, Osaka University, Japan
}

${ }^{\dagger}$ I am grateful to Matthew Shum for his suggestions and encouragement for the initial version of the paper. I would like to thank Kazunari Kainoh for the discussion on the industry, and seminar participants at Aoyama Gakuin University; GRIPS; JFTC; Keio University; KISER; Kobe University; Kyoto University; Nagoya University; Osaka University; and University of Tokyo, for their useful comments. Nobuo Hanafusa provided outstanding research assistance.

$\ddagger$ Institute of Social and Economic Research, Osaka University, 6-1 Mihogaoka, Ibaraki, Osaka 567-0047, Japan. Tel.: +81-6-6879-8581; fax: +81-6-6878-2766; e-mail: a-suzuki@iser.osaka-u.ac.jp. 


\section{(Abstract)}

This study examines the effect of yardstick regulation in Japan's gas distribution sector, especially focusing on its effect of reducing the adverse selection problem. The Japanese government has regulated the price of city gas supplies by a combination of fixed-price regulation and ex-ante yardstick regulation. The yardstick compares a firm's reported costs with those of "similar" firms before the price is determined. Realizing that yardstick inspection will lead the industry to a full-information outcome if it works perfectly, we infer its effect from the difference between the current and the counterfactual full-information welfare levels.

We estimate the cost function of retail gas distributors under the assumption of asymmetric information between the regulator and the distributor in the efficient level of labor. The estimation allows us to obtain informational parameters such as firms' efficiency levels and effort levels. Using the estimated cost structure and the firms' behavior in response to the regulatory incentive, along with the demand system and the behavior of the regulator, we calculate the current and the hypothetical full-information welfare levels, and examine whether the discrepancy of the current level from the full-information one has been significantly reduced since the introduction of yardstick regulation. Our results suggest that, on average, yardstick regulation reduces welfare discrepancy, implying it is somewhat effective in reducing firms' incentive to report higher costs. This effect, however, comes mainly from the very first inspection conducted in 1995. There seems to be a dynamic problem, similar to the Ratchet effect, because subsequent inspections cannot be effective for a firm that has learned the relative position of its own cost in the comparison group.

Keywords: Adverse selection, Yardstick competition, Incentive regulation, Relative performance evaluation

JEL Classification: L0, L12, L51, L95, K23 


\section{Introduction}

Since the seminal work of Shleifer (1985), yardstick competition has been recognized as an instrument for reducing the problems of asymmetric information, namely the adverse selection and moral hazard problems, faced by regulators when regulating firms. This regulation has gained increased attention in the debate about optimal incentive structures in retail distribution. However, there have not been many empirical studies of such a relative performance evaluation despite the increased number of formal applications of this measure, and the need for further empirical evidence is not diminishing. ${ }^{12}$ The purpose of this paper is to contribute to the debate on yardstick regulation. The paper examines the effect of yardstick regulation in Japan's gas distribution sector, especially focusing on its effect of reducing the adverse selection problem.

The Japanese government (the Ministry of Economy, Trade and Industry or METI) regulates the price of city gas supplies. The price of gas is determined by a type of fixed-price regulation. As is well known, while this type of contract has a high-powered incentive scheme to induce regulated firms to exert the best efforts because the firms are residual claimants, it does not have any truth-telling mechanisms. Presumably to improve such regulation, the METI introduced socalled "yardstick inspection" in 1995. This inspection system compares a firm's reported costs with those of "similar" firms before the price is determined. Firms that report relatively higher costs are subject to penalty. The reported costs are reduced and the price is determined based on these adjusted costs. Such a relative performance system may effectively reduce the regulator's

\footnotetext{
${ }^{1}$ The yardstick competition has been implemented in utility industries in many countries, such as: the electricity industry in the UK, Switzerland, Chile, and Germany; the water industry in the UK and Italy; the bus industry in Norway and so on.

${ }^{2}$ As exceptions, there exist some empirical studies related to yardstick competition. For example, Farsi and Filippini (2004) measure the cost efficiency of electricity distribution utilities in Switzerland. Studies such as Antonioli and Filippini (2001) and Yatchew (2001) discuss how benchmarks should be constructed using the data from Italy's water and Canada's electricity distribution utilities, respectively. Dalen and Gómez-Labo (2003) investigated to what extent different types of regulatory contracts affect company performance in Norway's bus industry, and found that a yardstick type of regulation significantly reduces operating costs. Our study differs from these previous studies in the way that it uses a structural model that explicitly takes into account the information problem in the regulatory environment. Moreover, most of the above studies focus on the discussion about firms' incentive to behave in a more cost-effective manner, but not about their incentive for information revelation. Our study, however, focuses on the latter incentive.
} 
ex-ante information disadvantage by inducing firms to compete against each others and eliminating firms' incentive to report higher costs. Thus, the new regulation system, which combines the fixed-price contract with yardstick inspection, should effectively eliminate both ex-ante adverse selection and ex-post moral hazard problems, the former by yardstick inspection and the latter by the fixed-price contract.

However, several practical problems are associated with yardstick regulation. The main problem is the comparability between agents (see Shleifer (1985), Yatchew (2001)). For basic yardstick regulation to work, all distributors must produce under the same condition. This condition is unlikely to hold for regional monopolists such as Japanese gas distributors. The second problem is the possibility of firms colluding (see Shleifer (1985), Tangerås (2002) and Potters et al. (2004)). These problems may reduce the effectiveness of yardstick competition. Having recognized these problems, the objective of the study is to assess whether and to what extent the yardstick in the Japanese gas distribution sector works effectively.

We show that, if yardstick inspection works perfectly, that is, the current industry exhibits desirable conditions and does not face the problems pointed out above, the current welfare level converges to the counterfactual full-information welfare level. On the other hand, if yardstick inspection does not work well, then the welfare difference should persist. The idea of this study is to infer the effect of yardstick inspection by the difference between the current and the fullinformation welfare levels.

Using firm-level panel data of local distributors, we estimate the cost function of the Japanese gas retail distribution sector based on Laffont and Tirole (1986). This estimation procedure was first introduced by Gagnepain and Ivaldi (2002). The estimation allows us to obtain informational parameters such as firms' efficiency levels and effort levels. Using the estimated cost structure and the firms' behavior in response to the regulatory incentive, along with the demand system and the behavior of the regulator, we calculate the current and the hypothetical full-information welfare levels, and examine whether the discrepancy of the current level from the full-information one has been significantly reduced since the introduction of yardstick inspection. The results suggest that, on average, yardstick inspection reduces the welfare discrepancy, implying it is effective in reducing firms' incentive to report higher costs. This effect is, however, mainly a result of the very first inspection conducted in 1995 . There seems to be a dynamic problem, similar to the Ratchet effect, because subsequent inspections cannot be 
effective for a firm that has learned the relative position of its own cost in the comparison group.

The structure of the paper is as follows. The next section reviews the existing literature. Section 3 describes the existing regulation in the Japanese gas distribution industry. Section 4 considers the application of the theory of Laffont and Tirole (1986) to the industry in order to construct the structural model. Section 5 presents our empirical model and estimation method, and the results are shown in Section 6. In Section 7, the welfare levels-current and full informationare calculated and the welfare implications of the yardstick inspection are presented. The last section concludes the paper.

\section{Previous Studies}

The asymmetric information problems in the regulatory environment arise as follows. A firm's cost opportunities may be high or low based on its inherent attributes. Typically, the firm has better information on its own cost opportunities. The firm would like to convince the regulator that it is a "higher cost" firm than it actually is, in the belief that the regulator will then set higher prices for the services it provides. Thus, the social-welfare-maximizing regulator faces a potential adverse selection problem as it seeks to distinguish between firms with high cost opportunities and firms with low cost opportunities. Furthermore, a firm's realized costs will depend not only on its underlying cost opportunities but also on the behavioral decisions made by managers to exploit these cost opportunities. While such managerial effort will lower the firm's costs, other things being equal, exerting more managerial effort imposes costs on managers. The regulator cannot observe managerial effort directly and thus, faces a potential moral hazard problem associated with variations in managerial effort in response to regulatory incentives. For more than 20 years, there have been many theoretical studies to find the optimal regulation when there is information asymmetry between a regulator and regulated firms. There are two strands of such literature. One uses the principal-agent framework to assess the optimal regulation, namely individual incentive regulation, while the other uses a relative performance mechanism, namely yardstick regulation. ${ }^{3}$

The representative studies on the theory of individual incentive regulation are Baron and Myerson (1982) and Laffont and Tirole (1986), both of which examine optimal regulation when the regulated firm has superior information about its costs. They differ in that the former focuses

\footnotetext{
${ }^{3}$ See Chong (2003) for an extensive literature review of incentive regulation.
} 
on the problem of hidden information while the latter considers both hidden information and hidden action problems. The optimal regulation is the one that maximizes social welfare under the incentive compatibility and participation constraints.

Yardstick regulation was first introduced by Shleifer (1985) as an incentive regulation. He shows that if there are multiple noncompeting but otherwise identical firms, an efficient regulatory mechanism involves setting the price for each firm based on the realized costs of the other firms. Then each individual firm has no control over the price it will be allowed to charge; each firm effectively has a fixed-price contract and will exert the best effort. While Shleifer (1985) considers the case where there is no adverse selection and where the firm's performance depends deterministically on its effort, Tangerås (2002) shows that yardstick competition can help the regulator in compelling firms to reveal their private information. He uses the stochastic structure in Auriol and Laffont (1992) where firms' adverse selection parameter $\beta_{i}$ is comprised of two parts: a common random variable $m$ and an idiosyncratic one $\varepsilon_{i}$, as follows:

$$
\beta_{i}=\alpha m+(1-\alpha) \varepsilon_{i}, i=1,2,
$$

where $\alpha$ is a measure of the correlation between firms, and subscript $i$ represents a firm. In Tangerås (2002), firms are first asked to submit a report on their common adverse selection parameter. Because the regulator can dissuade any untruthful reports, information asymmetry is reduced.

The empirical studies that explicitly consider the asymmetric information problems in the regulatory environments seem to have appeared much later, possibly because there are unobservable variables that play a key role in the model, but for which data cannot be obtained. Recent empirical studies such as Wolak (1994) and Gagnepain and Ivaldi (2002) cope with such difficulties by using distributional assumptions on those variables. In the theory of individual incentive regulations, it is usually assumed that the regulator at least knows the distribution of the parameter responsible for the asymmetric information, and the recent empirical studies use this assumption directly for their estimation. Both Wolak (1994) and Gagnepain and Ivaldi (2002) assume that there is information asymmetry in labor inefficiency. That is, the observed physical labor is different from the efficient level of labor while the former determines the operational cost and the latter determines the output level. The studies compare the estimation results of the two models with different informational assumptions, one under the assumption of asymmetric information and the other without it, and show that the asymmetric information model can explain the data better. The difference between these two studies is the same as that 
between Baron and Myerson (1982) and Laffont and Tirole (1986): Wolak (1994) considers the case of hidden information, while Gagnepain and Ivaldi (2002) consider both hidden information and hidden action problems. Another main difference is that Wolak (1994) assumes the optimality of the existing regulation while Gagnepain and Ivaldi (2002) do not. Wolak (1994) first presents the optimal regulation in the California water supply industry and assumes the firms are acting under such regulation. He then tests whether the data can be explained by such behavior. On the other hand, Gagnepain and Ivaldi (2002) estimate the parameters of a cost function for the French transit system treating the existing regulation as given. Then, using those parameters, they calculate and compare the welfare levels under the existing regulation and the optimal regulation.

\section{Overview and Data}

In Japan, entry to the gas distribution business is regulated and therefore, to prevent the existing distributors from charging an inappropriate rate, the price of gas supply is regulated by the METI. This section provides a brief overview of the industry and associated regulation.

In 2006, the Japanese gas retail distribution sector consisted of 226 firms, most of which are very small and local. While some distributors are partially or entirely vertically integrated, most of them have no significant production of their own. The large vertically integrated distributors import inputs such as liquefied natural gas or liquefied petroleum gas and vaporize them within the country. The small independent distributors generally purchase vaporized gas from such large integrated firms or use national natural gas in their local markets. Distribution is handled by both private distributors and distributors owned by prefectures or cities. There were 174 private and 52 public distributors in 2006. They are regional monopolists and supply gas services in a certain area. We consider each regional monopolized market during a time period as a realization of a regulatory contract.

We use the data of the public distributors for our analysis. While it is certainly our interest to analyze the private distributors, only the data of listed private distributors are available from the database, which is a very small portion of the entire population. Furthermore, pooling private and public distributors is not desirable because their size and input structure differ significantly. Therefore, we decided to focus on public distributors in this study. We use the gas section of Chiho Koei Kigyo Nenkan, which contains data on costs and production structure for all public 
companies in Japan. Unless otherwise noted, data are taken from this source. This provides us with a sample of 76 public gas distributors for the period 1990-2005.

Our sample can be classified into three categories according to technology. The first type does not have any vaporization or reformer systems and purchases vaporized gas from large integrated distributors or uses national natural gas. The second type includes those with vaporization systems. They purchase liquefied natural gas from large distributors and vaporize it on site. The last type owns reformer systems that enable them to convert liquefied petroleum gas to city gas. The gas jigyo binran states how each distributor is classified. Because of the technological differences, the cost structures of the three types differ significantly. For example, the first type incurs low input costs as vaporized gas is transported through conduits, while the second type transports liquefied natural gas by tank trucks, which is very costly. Therefore, for the purpose of homogeneity, we use only the first type of distributors for the estimation of the cost function. This leaves us with an unbalanced panel of 59 distributors for the estimation in the sample period.

Japanese gas retail distributors need to obtain permission from the METI when they change price. ${ }^{4}$ Based on the expected future demand for a certain number of coming years (one year for the existing distributors, three years for the new distributors), price $P^{r}$ is determined to satisfy the equation below:

$$
P^{r} Y^{e}=C\left(Y^{e}\right)+s B
$$

where $Y^{e}$ is the expected demand, $C\left(Y^{e}\right)$ is the expected operating cost to meet the expected demand, $s$ is the rate of return, and $B$ is the rate base. Specifically, for private distributors, $s$ is the weighted average of the rates of return on equity capital and liability, and $B$ is the sum of operational capital and fixed assets. For public distributors, $s B$ is the interest expense on enterprise loans, temporary loans and money transferred, plus less than 2 percent of the average

\footnotetext{
4 This requirement has been abolished for voluntary price reductions since 1998. Distributors are only required to report in the case of voluntary price reduction. (There have been, however, only two cases of such voluntary price reduction among our samples during the sample period. Non-voluntary price reduction includes those due to structural change such as calorific value change. In such cases with structural changes, distributors still need to obtain permission for a price reduction). Furthermore, for large suppliers, entry and pricing have been deregulated since 1995. Our study focuses on small supply services that are still under regulation.
} 
of beginning and ending fixed assets. Thus $s B$ can be considered a capital cost. Gas distributors report each item of the above equation and the METI investigates whether the equation holds. There is no ex-post inspection.

This regulation scheme does not have a truth-telling mechanism if there is asymmetric information on the distributor's costs. ${ }^{5}$ The distributor has an incentive to report higher costs because that will make the regulated price higher and the profit allowed higher. ${ }^{6}$ On the other hand, this regulation is the perfect mechanism to prevent moral hazard because the distributor is a residual claimant. Note that the regulation is different from the traditional average cost pricing because price is determined based on expected costs, not on realized costs. Once the price is determined, the distributor can obtain higher profit as they increase effort to reduce costs. That is, the regulation is a type of fixed-price contract.

Presumably to mitigate the hidden information problem, the government introduced a so-called "yardstick inspection system". The METI inspects the costs of each distributor and compares them with similar types of distributors. The inspection procedure is as follows. First, the distributors are categorized into 16 groups according to the size of markets (the number of households in a market), the production system, inputs, location, and owner (public or private) of the distributor. Figure 1 shows this grouping. Then, the distributors in each group are graded from 0 to 200 for their reported costs. Based on this grade, the distributors in each group are again categorized into three groups: I, II, and III. Distributors with lower costs go into group I. Distributors in groups II and III are subject to a penalty. The reported costs of the distributors in those two groups are reduced and prices are determined based on the adjusted costs. ${ }^{7}$

\footnotetext{
${ }^{5}$ Theoretical literature such as Lewis and Sappington (1988) assumes information asymmetry on the demand side. That is, they assume that the firm has better information on the demand function than the regulator does. Although this assumption would be worth testing, in this version of the paper, we focus on information asymmetry on the supply side. The METI have local offices throughout Japan and the local offices are responsible for inspection of local distributors. We could argue that because of these local offices, the METI is able to obtain good information on local demand and that there is little asymmetric information on demand. If information asymmetry on demand is present, suppliers may have an incentive to report lower expected demand.

${ }^{6}$ More specifically, reporting higher costs leads to a higher (lower) regulated price if the demand elasticity is enough low (high) (see Section 7).

${ }^{7}$ For now, the reduction rates are $0.5 \%$ for group II and $1 \%$ for group III.
} 
$<<$ Insert figure 1 about here >>

Although Japanese yardstick inspection is not identical to the textbook type of yardstick competition, it does have its essence. If the penalty is large enough, the regulation reduces the incentive of firms to report higher costs (given firms in each group are actually very similar) because if a firm lies and others report the truth, then the firm that lied will be punished. Thus, the current regulation, which combines a yardstick and a fixed-price contract, theoretically eliminates both adverse selection and moral hazard problems: yardstick inspection removes the adverse selection problem while a fixed-price contract removes the moral hazard problem. In addition, because a yardstick system does not require the regulator to give firms an informational rent to tell the truth, the current regulation may indeed lead the industry to the full-information outcome. ${ }^{89}$

In practice, however, it seems difficult for the yardstick system to work perfectly to remove the adverse selection problem. First, it has often been discussed that the regulator is unlikely to find a large set of truly identical firms. In this Japanese system, distributors cannot be identical even in the same group. Second, again as an often-discussed point, firms may collude. Third, the current penalty seems to be ad hoc. It is unclear if it is sufficiently high to induce truth telling. Furthermore, here, the extent of the punishment depends only on the order of the costs, not on the difference in the costs. This may also reduce the effectiveness of the regulation.

Because yardstick inspection is unlikely to work perfectly, we do not assume optimality of the current regulation. Therefore, our estimation follows Gagnepain and Ivaldi (2002) rather than Wolak (1994). This estimation requires only ex-post realized data and we do not have to model the firms' ex-ante behavior under yardstick inspection. This suits us because we are not sure to what extent the Japanese yardstick is effective and therefore, how the firms behave under such regulation: we cannot model ex-ante behavior of the firms. As described before, we infer such ex-ante behavior of firms, truth telling or not, by the welfare difference.

\footnotetext{
${ }^{8}$ With an individual incentive regulation, the regulator cannot achieve the full-information outcome because it needs to give informational rents to firms, and usually such rents are costly.

${ }^{9}$ We mean, by full-information outcome, the counterfactual outcome that can be achieved if the regulator does not face the information disadvantage. This differs from the often-discussed first best outcome because the regulator here is not a welfare maximizer. See Section 7 for the discussion of the Japanese regulator's objective.
} 
All the gas distribution companies were surveyed in the first yardstick inspection in 1995. They were required to provide values for the variables in equation (1), regardless of whether they were willing to change their current prices. Following the first inspection, only the distributors that applied for a price change are subject to yardstick inspection. Among our sample of 59 distributors, there were 14 applications for price changes subject to the yardstick after 1995, one each in 2000 and 2003, two in 2001, four in 2004, and six in 2005. When only the distributors that applied for a price change are inspected, the latest reported costs of firms that did not apply for a price change (they did not report current costs) are used as a benchmark.

Figure 2 shows the average unit price of public firms over 1990-2005. The prices of public firms have a downward trend after the introduction of yardstick inspection. There is a large drop in prices in 1996, following the introduction of yardstick inspection.

\section{$<<$ Insert figure 2 about here $>>$}

\section{Theoretical Model}

In this section, we consider a model of retail gas distribution services, which is still under price regulation. ${ }^{10}$ To derive a structural model of the industry, we need a detailed account of the technological, informational, and regulatory constraints. We start this section by describing our assumptions on these constraints.

For the technological constraint, we assume that, to provide the required level of services, denoted by $Y$, the gas distributor needs to combine four inputs: labor $(L)$, gas $(G)$, materials $(M)$, and capital $(K)$. $L$ includes all types of workers; $G$ corresponds to gas inputs for distribution; $K$ refers to plant, infrastructure, and distribution networks; and $M$ includes all materials used for performing maintenance and management activities. The distribution process is then represented as:

$$
Y=f(L, G, M, K \mid b),
$$

where $b$ is a vector of parameters characterizing the technology in the production process.

\footnotetext{
${ }^{10}$ As noted, prices for large supply services were deregulated in 1995.
} 
Regarding informational and regulatory constraints, we follow the assumptions of Gagnepain and Ivaldi (2002) (henceforth G\&I). First, the gas distributor has private information about its technology and its cost-reducing effort is unobserved by the authority. We assume that the distributor is better informed about input efficiency than the regulator is. More specifically, we distinguish between the observed and the efficient levels of labor and assume that the distributor is better informed about labor efficiency. ${ }^{11}$ Second, regulatory schemes and distributors' efficiency levels are exogenous. ${ }^{12}$

Let $\hat{L}$ be the physical amount of labor that is observable by the authority. $L$ is the efficient level of labor associated with the output level $Y$. We assume that the ratio of observed to efficient labor quantities is a direct measure of informational discrepancies between the regulator and the distributors. Following G\&I:

$$
\hat{L}=L \exp (\theta-e)
$$

Parameter $\theta$, the so-called "labor inefficiency parameter", refers to variables that are not under the control of the distributor. As $\theta$ becomes larger, the efficient level of labor is smaller given the observed physical amount of labor. The variable $e$ summarizes the behavioral decisions made by managers to exploit the opportunities; $e$ defines the effort level of managers. As $e$ increases, the discrepancy between $L$ and $\hat{L}$ decreases. The distributors cannot change their types, $\theta$, but can change the level of discrepancy between $L$ and $\hat{L}$ by increasing the effort level $e$. If the distributor sets the effort level so that $e=\theta$, then the observed level and efficient level coincide. ${ }^{13}$ Both input inefficiency and cost-reducing activity are unobservable to the regulator and to the econometrician. The efficient level of labor $L$ determines the output level while costs are incurred to cover physical labor $\hat{L}$.

\footnotetext{
${ }^{11}$ For analytical simplicity, we assume that only one input is affected by this inefficiency although in reality all of the four inputs may be inefficient. Appraising efficiency by the observed quantity of physical input is more difficult in the case of labor and choosing labor input for the setting seems to be appropriate.

${ }^{12}$ The assumption that the efficiency parameter is independent of time is debatable. This implies that contracts are renewed each year independently of what the state of nature was in the past. In a dynamic setting, inefficiency could evolve, and its evolution could be approximated by a trend. (See Cornwell, Schmidt, and Sickles (1990) for such a model.)

${ }^{13}$ We assume that $\theta$ is always greater than $e$. As Gagnepain and Ivaldi stated, this assumption is meaningful in the sense that the managers' effort is aimed at reducing the inefficiency level, which cannot be larger than $\theta$.
} 
Next, we interpret the distributors' decision process after the price is set. The decision process consists of choosing the optimal input and effort allocation. Note that this is an ex-post behavior and does not involve an ex-ante decision process, such as which level of costs to report, under the yardstick regulatory environment. We decompose this ex-post decision process into two steps. The first step is to choose the optimal input and the second is to choose the optimal effort allocation, given the regulated price and the demand associated with the price.

Assuming that the distributor is a price-taker in the market for input factors and has a costminimizing behavior for each level of effort, an operating cost function can represent the technological process. The operating cost faced by the distributor is:

$$
C=\omega_{L} \hat{L}+\omega_{G} G+\omega_{M} M,
$$

where $\omega=\left[\omega_{L}, \omega_{G}, \omega_{M}\right]$ are the prices of labor, gas, and materials, respectively. We assume that $K$ cannot be fully adjusted in the short run and is fixed. ${ }^{14}$ From duality theory, the conditional operating cost function is defined by:

$$
C(Y, K, \omega, e, \theta \mid \beta)=\min _{L, G, M} \omega_{L} L \exp (\theta-e)+\omega_{G} G+\omega_{M} M,
$$

subject to:

$$
Y=f(L, G, M, K \mid b) .
$$

Equation (4) defines a "conditional" operating cost function because it still contains a level of effort. This is the first step in the distributors' decision process.

The second step is to determine the level of cost-reducing activity under the given regulatory environment. As seen in the previous section, the Japanese authority sets the price of gas services so that it equals the expected average cost (see equation 1). There is no ex-post inspection to check whether the reported cost is actually equal to the realized cost. Under this fixed-price regulation, the distributor is the residual claimant of effort. After the activity in the contractual period, all the realized profit goes to the distributor. The utility of the firm is given by:

$$
U=P(Y) Y-C(Y, K, \omega, e, \theta \mid \beta)-s B-\psi(e),
$$

where $\psi(e)$ is the cost of effort function; exhibiting effort is costly for the firm. The distributor

\footnotetext{
${ }^{14}$ We also assume that the capital cost $s B$ is fixed in the short term and therefore it is included not in the operating costs but in the total cost.
} 
maximizes utility in equation (5) with respect to the effort level, $e$, and the first-order condition is:

$$
\psi^{\prime}(e)=-\partial C / \partial e,
$$

which implies that the marginal cost of effort equals the marginal cost saving from the effort.

\section{Empirical Model}

\subsection{Functional forms}

We choose a simple Cobb-Douglas function to represent technology for the following reasons. First, we use it for tractability. Although we could have used more elaborate functional forms such as a translog for the estimation of the cost function, computations of welfare become cumbersome with such functions. Second, because of the choice of the Cobb-Douglas function, the two-step decision process above (the input allocation and effort level determination problems) provides the same solution as if we had solved the two steps simultaneously. Under Cobb-Douglas technology, the dual cost function is given by:

$$
C=\beta_{0} \exp \left[\beta_{L}(\theta-e)\right] \omega_{L}^{\beta_{L}} \omega_{G}^{\beta_{G}} \omega_{M}^{\beta_{M}} K^{\beta_{K}} Y^{\beta_{Y}},
$$

with the assumption of homogeneity of degree one in input prices, that is $\beta_{L}+\beta_{G}+\beta_{M}=1$. We should note that no constraint is imposed on the return to scale effect. As in previous studies, we specify the cost of effort by:

$$
\psi(e)=\exp (\alpha e)-1
$$

with $\alpha>0$.

Using these functional forms and the first-order condition (6), we can solve for the effort level as:

$$
e^{*}=\frac{\beta_{L} \theta+\ln \beta_{L} \beta_{0}-\ln \alpha+\beta_{L} \ln \omega_{L}+\beta_{G} \ln \omega_{G}+\beta_{M} \ln \omega_{M}+\beta_{K} \ln K+\beta_{Y} \ln Y}{\alpha+\beta_{L}} .
$$

From the equation above, we can see that the equilibrium effort level under this regulation regime is an increasing function in the inefficiency parameter $\theta$, the output level $Y$, and the input prices $\omega_{L}, \omega_{G}$, and $\omega_{M}$. A distributor with the larger $\theta$ (less efficient distributor) needs to make a greater effort under this regulatory scheme. Moreover, $e^{*}$ is a decreasing function of $\alpha$, the technological parameter of the internal cost function (8).

Substituting the optimal effort level $e^{*}$ into the cost function (7) and taking the logarithm, we 
obtain the cost function as follows:

$$
\ln C=\beta_{0}^{\prime}+\xi\left(\beta_{L} \theta+\beta_{L} \ln \omega_{L}+\beta_{M} \ln \omega_{M}+\beta_{G} \ln \omega_{G}+\beta_{K} \ln K+\beta_{Y} \ln Y\right),
$$

where $\xi=\alpha /\left(\alpha+\beta_{L}\right)$ and $\beta_{0}^{\prime}=\ln \beta_{0}+\beta_{L}\left(\ln \alpha-\ln \beta_{L}-\ln \beta_{0}\right) /\left(\alpha+\beta_{L}\right)$.

\subsection{Estimation method and data}

The key feature of G\&I lies in the way a stochastic element is built into the classical Cobb-

Douglas cost function through the efficiency parameter. Assuming that parameter $\theta$ has a density function $f(\theta)$ defined over an interval $[\underline{\theta}, \bar{\theta}]$, where $\underline{\theta}$ ( $\bar{\theta}$ respectively) corresponds to the most (least) efficient firm, provides us with the stochastic element required to perform the estimation.

Using equation (10), the stochastic cost function for distributor $i$ at period $t$ is given as:

$$
\begin{aligned}
c_{i t} & =\beta_{0}^{\prime}+\xi\left(\beta_{L} \theta+\beta_{L} \ln \omega_{L}+\beta_{G} \ln \omega_{G}+\beta_{M} \ln \omega_{M}+\beta_{K} \ln K+\beta_{Y} \ln Y\right)+\varepsilon_{i t}^{c} \\
& =c\left(Y_{i t}, K_{i t}, \omega_{i t}, \theta_{i t} \mid \beta\right)+\varepsilon_{i t}^{c}
\end{aligned}
$$

where $c_{i t}=\ln C$ and an error term $\varepsilon^{c}{ }_{i t}$ is added to account for potential measurement errors. It is assumed to have a normal density with mean zero and variance $\sigma_{c}^{2}$, and they are independent of each other. Moreover, we use a beta density function for $f(\theta)$, the distribution of the efficiency index $\theta$, with scale parameters $\mu$ and $v$. It is reasonable to choose this distribution for $\theta$ because the shape of the beta distribution is flexible depending on the scale parameters. Furthermore, G\&I sets out two additional advantages of using the beta density function. First, the beta density function is defined over the interval $[0,1]$ and therefore, the labor inefficiency parameter is defined as a percentage. Second, we need a density function defined on a compact support and the beta density function gives us this condition.

The conditional likelihood of $\theta_{i}$ is:

$$
L_{i t}\left(\theta_{i t}\right)=L\left(c_{i t} \mid Y_{i t}, K_{i t}, \omega_{i t}, \theta_{i}, \beta, \sigma_{c}, \mu, v\right)=\frac{1}{\sigma_{c}} \phi\left[\frac{\varepsilon_{i t}{ }^{c}}{\sigma_{c}} \mid \theta_{i}\right],
$$

where $\phi($.$) denotes the normal density function. However, because the variable \theta_{i}$ is unobservable, only the unconditional likelihood can be computed, that is:

$$
L_{i t}=\int_{0}^{1} L_{i t}\left(u_{i}\right) u_{i}^{v-1}\left(1-u_{i}\right)^{\mu-1} \frac{\Gamma(v+\mu)}{\Gamma(v) \Gamma(\mu)} d u_{i},
$$

where $\Gamma($.$) is the gamma function.$ 
The sample consists of 76 public gas distributors for the period 1990-2005. As described in Section 3, the sample can be categorized into three types according to their technology. For the cost estimation, we use 59 distributors of Type 1 for the purpose of homogeneity. Estimating the Cobb-Douglas cost function requires measures of the level of operating costs, the quantity of output, and the input prices. The output is specified as total volume $\left(\mathrm{m}^{3}\right)$ of gas supplied by distributors. The total length of the conduit $(\mathrm{m})$ is used for the quantity of capital. Costs of labor are specified as total labor expenditures including wages, salaries, pensions, and benefits. The price of labor is calculated as labor costs divided by the number of employees. Costs of materials are specified as nonpersonnel expenses for day-to-day operations and maintenance of the distribution network. The price of materials is calculated as the costs of materials divided by the number of meters (that is, the number of households that have access to the gas supply service) in each market. Because the costs of materials mostly arise from operating and maintaining distribution lines to households, the number of households seems to be a suitable measure of material inputs. Costs of gas input are specified as total expenditure on raw material inputs. The price of gas is calculated as the costs of gas divided by the total amount of gas used for distribution.

For welfare analysis, we estimate the demand function in Section 7 . We use all 76 samples for the demand estimation. This estimation additionally requires measures of consumer prices. We use the calorific value-adjusted price (yen/10,000 kcal) as the price measure. Furthermore, welfare calculation requires the capital $\operatorname{cost}, s B$ in equation (1). Capital cost is specified as interest expenses on enterprise loans, temporary loans, and money transferred plus 2 percent of the average of the beginning and ending fixed assets.

Summary statistics of the variables categorized according to their technology types are given in Table 1.

Table 2 compares the average operating costs and prices before and after the introduction of yardstick inspection. We can see from the last row that, in our sample, both the mean average operating cost and the mean price decreased after the introduction of yardstick competition. These changes are statistically significant. The standard deviations of costs and prices also decreased after the introduction of yardstick inspection, although the latter is statistically insignificant. We examine these statistics in each group of the yardstick inspection; however, 
some groups show different changes. In group 15, the mean of prices increased, despite a decrease in the mean of costs, after the introduction of yardstick inspection. In groups 12 and 15, the standard deviations of prices increased after the introduction of yardstick competition. Furthermore, Table 2 compares the mean growth rates of average cost before and after the introduction of yardstick inspection. We can see from the last row that, in our sample, the average operating costs were decreasing in the sample period. These decreases are not significantly different between the two periods at 5 percent level. In group 14, however, average operating costs were increasing before the introduction of yardstick inspection, while they were decreasing afterward.

\section{Estimation Results}

\subsection{Estimation results of cost function}

The estimated parameter values for equation (11) are reported in Table 3. Because we assumed homogeneity, the parameter for $\beta_{M}$ is dropped. To capture the time trend, we add a year dummy to equation (11), and $\beta_{t}$ denotes its coefficient.

All parameters are significant at least 10 percent level, except $\alpha$ and $\beta_{t}$. In particular, this is true for the scale parameters $\mu$ and $v$ characterizing the density of the inefficiency level. From the estimated $\mu$ and $v$, it turns out that the density function is a decreasing function. More than 70 percent of the distributors have a $\theta$ of less than 0.5 .

Along with the above model, we also estimate the alternative model. The alternative model is a Cobb-Douglas cost function that does not take into account regulatory and informational constraints. This model is referred to as the standard case, namely:

$$
\ln C_{i t}=\beta_{0 i}+\beta_{L} \ln \omega_{L, t i}+\beta_{M} \ln \omega_{M, i t}+\beta_{G} \ln \omega_{G, i t}+\beta_{Y} \ln Y_{i t}+\beta_{K} \ln K_{i t}+\beta_{t} \ln Y e a r+\varepsilon_{i t}{ }^{c} .
$$

The standard case includes a time trend and a firm effect $\beta_{0 i}$ to allow for a fixed-effect estimation procedure. To compare the fit of the two models, we conducted a Vuong (1989) test whose null hypothesis is that the two models are equally far from the true data-generating process in terms of Kullback-Liebler distances. The alternative hypothesis is that one of the two models is closer to the true data-generating process. We obtain a Vuong statistic of 2.67. This statistically supports the asymmetric information model generated by the structural approach rather than the standard model. 


\subsection{Efficiency and effort levels}

Estimates of individual efficiency parameters can also be recovered. From equations (10) and (11), the error term of the cost function has two unobservable, random, and independent components, $\theta_{i}$ and $\varepsilon_{i t}{ }^{c}$. The error term can be written as:

$$
u_{i t}=\varepsilon_{i t}{ }^{c}+\xi \beta_{L} \theta_{i},
$$

where $\xi=\alpha /\left(\alpha+\beta_{L}\right)$. From a procedure by Jondrow et al. (1982), we recover an estimate for

each $\hat{\theta}_{i}$ from the values of residuals $\hat{u}_{i t}$ by considering the conditional distribution of $\theta_{i}$ given $u_{i t}$, that is, by computing $\hat{\theta}_{i}=E\left(\theta_{i t} \mid u_{i t}\right)$. For all distributors in our data set, the estimated values of the efficiency levels are available from the authors. Once the estimate for $\theta_{i}$ is obtained, we can then also obtain the effort level using equation (9).

From equation (7), the cost distortion that measures the discrepancy between the theoretical frontier and the observed cost is given by:

$$
\exp \left[\beta_{L}(\theta-e)\right] .
$$

The maximum cost distortion is achieved for a zero level of effort and an inefficiency level equal to one. Figure 3 presents our set of distributors in 1996 ranked according to their cost distortions defined by equation (15). In addition, Figure 3 provides the level of the inefficiency parameter for each distributor. Reflecting the high efficiency levels and the high-powered incentive regulatory scheme (that is, fixed-price contract), the distortion is not very high. The maximum distortion is about 10.1 percent, and most of the distributors exhibit a distortion level of less than 5 percent.

$<<$ Insert figure 3 about here $>>$

\section{Welfare Implications and the Effect of Yardstick Inspection}

\subsection{Demand}

Our objective is now to perform a comparison of current and full-information welfare. First, to compute consumer surplus, the price elasticity of demand must be estimated.

Assume the demand function is $\log$ linear such that:

$$
\ln Y=d_{0}+d_{1} \ln P+d_{2} t+\varepsilon_{d},
$$


where a vector $d_{0}$ includes the fixed effects and $t$ is a year dummy. Our model of costs and the demand systems is sequential. First, the government sets a price and once the price is known, the demand level is determined according to equation (16). Finally, the cost of running the service is obtained through the cost model given by equation (10). This gives rise to a blockrecursive structure, so each equation can be estimated separately. We obtained the estimated results of price elasticity 0.275 . See Table 4 for the results.

\subsection{Regulator's behavior}

We now know the cost structure, the demand elasticity, the inefficiency level, the effort function, and the price level. Additionally, the behavior of the regulator must be specified. Here, we consider the regulator's pricing behavior, ignoring the existence of the yardstick regulation for now. As noted in Section 3, the regulation requires the price to be equal to an expected average cost as in equation (1): $P^{r}=\left(C\left(Y^{e}\right)+s B\right) / Y^{e}$. Therefore, we assume that the regulator's objective is to set the price equal to the average cost such that:

$$
P^{r} Y=C(Y)+s B
$$

where $\mathrm{Y}$ is the realized output level. ${ }^{15}$ Given the selected price is a point on the inverse demand function, $P($.$) , when the authority has set the price, the associated demand Y$ is implicitly determined, that is, the customers adjust their demand at this price. The regulator should take this into account and therefore, equation (17) can be rewritten as:

$$
\begin{aligned}
P(Y) Y & =C(Y)+s B \\
& =C(Y, K, \omega, e, \theta \mid \beta)+s B
\end{aligned}
$$

where the cost function in equation (4) is substituted. The regulator's problem is to find the demand level $Y$ that satisfies the equation above, given $K, \omega, e, \theta, \beta$, and $s B$.

We assume that the regulator observes all the variables and the parameters in the above equation except $\theta$ and $e$. Actually, however, from equation (9), once the level of $Y$ is determined, the level of effort can be recovered if $\theta$ is recovered: $e=e^{*}(Y, K, \omega, \theta \mid \beta)$. The regulator is assumed to know this structure of the industry and therefore, the only unobservable for the

\footnotetext{
${ }^{15}$ Gagnepain and Ivaldi (2002) assume that the regulator is a welfare maximizer, given the regulatory environment. However, because it is not welfare maximizing to set the price to be equal to the average cost, we do not assume it here. Therefore, our full-information welfare is different from the first-best welfare unlike often discussed, and the current welfare may be larger than the full-information welfare.
} 
regulator is $\theta$.

Given the above assumptions, the regulatory environment is reduced to the following. First, the distributor reports the levels of $K, \omega, \theta$ and $s B$, and the regulator sets the level of output so that equation (18) holds, given the reported levels. Because $K, s B$ and $\omega$ are observed by the regulator, we assume that the distributor reports the true levels of these variables; they are the same as the observed data. On the other hand, because the regulator does not observe the level of $\theta$, we distinguish the true level of $\theta$ from the reported level $\hat{\theta}$. We assume that the regulator believes that $\hat{\theta}=\theta$. Given the reported inefficiency level $\hat{\theta}$, the regulated output level $Y^{r}$ is determined so that:

$$
\begin{aligned}
P\left(Y^{r}\right) Y^{r} & =C\left(Y^{r}, K, \omega, e^{*}\left(Y^{r}, K, \omega, \hat{\theta} \mid \beta\right), \hat{\theta} \mid \beta\right)+s B \\
& =\beta_{0} \exp \left[\beta_{L}\left(\hat{\theta}-e^{*}\left(Y^{r}, K, \omega, \hat{\theta} \mid \beta\right)\right)\right] \omega_{L}^{\beta_{L}} \omega_{G}^{\beta_{G}} \omega_{M}^{\beta_{M}} K^{\beta_{K}} Y^{\beta^{\beta_{Y}}}+s B
\end{aligned}
$$

where $e^{*}\left(Y^{r}, K, \omega, \hat{\theta} \mid \beta\right)=\frac{\beta_{L} \hat{\theta}+\ln \beta_{L} \beta_{0}-\ln \alpha+\beta_{L} \ln \omega_{L}+\beta_{G} \ln \omega_{G}+\beta_{M} \ln \omega_{M}+\beta_{K} \ln K+\beta_{Y} \ln Y^{r}}{\alpha+\beta_{L}}$.

We can see that the regulated output level can be expressed as a function of the reported inefficiency level: $Y^{r}=Y(\hat{\theta})$.

\subsection{Ex-post distributor's behavior}

Once the regulated output level $Y^{r}=Y(\hat{\theta})$ is determined, the distributor conducts costminimization activity (4) given $Y(\hat{\theta})$ and for each level of effort $e$, and the cost function is described as a function of both $\theta$ and $\hat{\theta}$, namely:

$$
C(\theta, Y(\hat{\theta}) \mid e)=\beta_{0} \exp \left[\beta_{L}(\theta-e)\right] \omega_{L}^{\beta_{L}} \omega_{G}^{\beta_{G}} \omega_{M}^{\beta_{M}} K^{\beta_{K}} Y(\hat{\theta})^{\beta_{Y}} .
$$

Similarly, the distributor next maximizes utility with respect to the effort level given the regulated output level $Y(\hat{\theta})$, and the first-order condition (9) gives us the effort level as a function of both $\theta$ and $\hat{\theta}$, namely:

$$
e^{*}(\theta, Y(\hat{\theta}))=\frac{\beta_{L} \theta+\ln \beta_{L} \beta_{0}-\ln \alpha+\beta_{L} \ln \omega_{L}+\beta_{G} \ln \omega_{G}+\beta_{M} \ln \omega_{M}+\beta_{K} \ln K+\beta_{Y} \ln Y(\hat{\theta})}{\alpha+\beta_{L}} .
$$

Therefore, the cost realization will be as the following,

$$
C\left(\theta, Y(\hat{\theta}), e^{*}(\theta, Y(\hat{\theta}))\right)=\beta_{0} \exp \left[\beta_{L}\left(\theta-e^{*}(\theta, Y(\hat{\theta}))\right)\right] \omega_{L}^{\beta_{L}} \omega_{G}^{\beta_{G}} \omega_{M}^{\beta_{M}} K^{\beta_{K}} Y(\hat{\theta})^{\beta_{Y}}
$$

\subsection{Welfare implications}

Given our knowledge of the demand and supply functions, we now calculate the welfare levels 
under the current and the hypothetical full-information situations to see whether the introduction of yardstick inspection reduces the information disadvantage of the regulator. Full-information welfare is obtained by assuming the regulator observes all the variables and parameters.

We define social welfare as:

$$
W=S-R+U
$$

where $S$ is the gross surplus and derived from the demand function, $R$ is the distributor's revenue and obtained as the product of the price and the demand level, and $U$ is the firm's utility defined in equation (4).

Substituting (21) and (22), the current (actual) welfare level $W^{c}$ can be expressed, given the reported inefficiency level $\hat{\theta}$ and the true inefficiency level $\theta$, as follows:

$$
W^{c}(\theta, \hat{\theta})=S(Y(\hat{\theta}))-P(Y(\hat{\theta})) Y(\hat{\theta})+\left[P(Y(\hat{\theta})) Y(\hat{\theta})-C\left(\theta, Y(\hat{\theta}), e^{*}(\theta, Y(\hat{\theta}))\right)-s B-\psi\left(e^{*}(\theta, Y(\hat{\theta}))\right)\right]
$$

This can be calculated by using the observed output level for $Y(\hat{\theta})$ and the inefficiency level $\theta$ recovered in Subsection 6.2. The full-information welfare level $W^{f}$, which can be obtained if a distributor reports the true inefficiency level $\theta$, that is, if $\hat{\theta}=\theta$, is:

$$
\begin{aligned}
W^{f} & =W^{c}(\theta, \theta) \\
& =S(Y(\theta))-P(Y(\theta)) Y(\theta)+\left[P(Y(\theta)) Y(\theta)-C\left(\theta, Y(\theta), e^{*}(\theta, Y(\theta))\right)-s B-\psi\left(e^{*}(\theta, Y(\theta))\right)\right]
\end{aligned}
$$

The problem with the fixed-price contract is that it does not have any truth-telling mechanism. Therefore, the distributors may have an incentive to report $\hat{\theta}$, which is higher than the true level $\theta$, to obtain a higher permitted profit. Such a behavior either decreases or increases social welfare away from the full-information welfare. ${ }^{16}$ Appendix A shows that reporting a higher inefficiency level $\hat{\theta}$ leads to a higher (lower) regulated price and lower (higher) output if the slope of the inverse demand curve is smaller (larger) than the average cost curve. It turns out that with our estimated parameter values, all our observed markets exhibit a smaller slope of the inverse demand curve than that of the average cost curve. Figure 4 describes this situation. In Figure $4, A C_{\theta}$ is the true average cost curve of a firm with inefficiency level $\theta$, and $A C_{\hat{\theta}}$ is the false average cost curve the regulator believes that the firm has when the firm reports $\hat{\theta}$ such

\footnotetext{
${ }^{16}$ As noted, the full-information welfare is different from the often-discussed first best welfare. Therefore, the current welfare can be higher than the full-information welfare.
} 
that $\theta<\hat{\theta}$. That is:

$$
\begin{aligned}
A C_{\theta}(Y) & =\frac{C\left(Y, K, \omega, e^{*}(Y, K, \omega, \theta \mid \beta), \theta \mid \beta\right)+s B}{Y} \\
& =\frac{\beta_{0} \exp \left[\beta_{L}\left(\theta-e^{*}(Y, K, \omega, \theta \mid \beta)\right)\right] \omega_{L}^{{ }^{\beta_{L}}} \omega_{G}{ }^{\beta_{G}} \omega_{M}{ }^{\beta_{M}} K^{\beta_{K}} Y^{\beta_{Y}}}{Y}
\end{aligned}
$$

where $e^{*}(Y, K, \omega, \theta \mid \beta)=\frac{\beta_{L} \theta+\ln \beta_{L} \beta_{0}-\ln \alpha+\beta_{L} \ln \omega_{L}+\beta_{G} \ln \omega_{G}+\beta_{M} \ln \omega_{M}+\beta_{K} \ln K+\beta_{Y} \ln Y}{\alpha+\beta_{L}}$, and

$$
\begin{aligned}
A C_{\hat{\theta}}(Y) & =\frac{C\left(Y, K, \omega, e^{*}(Y, K, \omega, \hat{\theta} \mid \beta), \hat{\theta} \mid \beta\right)+s B}{Y} \\
& =\frac{\beta_{0} \exp \left[\beta_{L}\left(\hat{\theta}-e^{*}(Y, K, \omega, \hat{\theta} \mid \beta)\right)\right] \omega_{L}^{\beta_{L}} \omega_{G}^{\beta_{G}} \omega_{M}^{\beta_{M}} K^{\beta_{K}} Y^{\beta_{Y}}}{Y}
\end{aligned}
$$

where $e^{*}(Y, K, \omega, \hat{\theta} \mid \beta)=\frac{\beta_{L} \hat{\theta}+\ln \beta_{L} \beta_{0}-\ln \alpha+\beta_{L} \ln \omega_{L}+\beta_{G} \ln \omega_{G}+\beta_{M} \ln \omega_{M}+\beta_{K} \ln K+\beta_{Y} \ln Y}{\alpha+\beta_{L}}$.

$P(Y)$ is the inverse demand function. In the full-information case, price is determined so that $P=A C_{\theta}$. This price and the associated demand are shown by $P(\theta)$ and $Y(\theta)$, respectively, in Figure 4. However, if the firm reports a higher $\hat{\theta}$, price and output are determined at the levels of $P(\hat{\theta})$ and $Y(\hat{\theta})$ in Figure 4. In such a case, the firm's true average cost is $A C_{\theta}(Y(\hat{\theta}))$ given the regulated output level $Y(\hat{\theta})$. The firm's profit increases from zero in the full-information case to the area $P(\hat{\theta}) a d A C(Y(\hat{\theta}))$. The firm's utility also increases, because the effort level decreases because of the lower output. Consumer surplus decreases because of a higher price and lower output.

$<<$ Insert figure 4 about here $>$

The introduction of yardstick inspection may reduce the incentive to report a higher $\hat{\theta}$, because if a distributor reports a higher inefficiency level than the other distributors in the same group, it is subject to penalty. In the next subsection, we show that if the yardstick inspection actually reduces the discrepancy between $\theta$ and $\hat{\theta}$, the difference between $W^{c}$ in equation (24) and $W^{f}$ in equation (25) should also decrease. We assess whether the introduction of yardstick inspection actually reduces the discrepancy between $\theta$ and $\hat{\theta}$ by examining whether the discrepancy between $W^{c}$ and $W^{f}$ has been reduced since its introduction.

\subsection{The effect of yardstick inspection}

The very first yardstick inspection was conducted in 1995. Under this first inspection, all gas 
distributors were required to report values of the variables in equation (1), regardless of whether they were willing to change their current prices at the time. Since the first inspection, only distributors that apply for a price change have been subject to yardstick inspection. Among our sample of 59 distributors, there were 14 applications for price changes that were subject to the yardstick after 1995, one each in 2000 and 2003, two in 2001, four in 2004, and six in 2005.

We call the first inspection, in which all the distributors are targets, the "simultaneous yardstick inspection" and the subsequent cases, in which the distributor that applied for a price change is the target, as the "individual yardstick inspection". We examine the difference between fullinformation welfare $W^{f}$ in equation (25) and current welfare $W^{c}$ in equation (24) or $\Delta W=W^{f}-W^{c}$, with and without yardstick inspection. Equations (24) and (25) show that as a reported inefficiency level converges to the true inefficiency level, the welfare difference converges to zero. That is, as $\hat{\theta} \rightarrow \theta, W^{c} \rightarrow W^{f}$ and $\Delta W \rightarrow 0$. Furthermore, Appendix B shows that with our parameter estimates, current welfare $W^{c}(\theta, \hat{\theta})$ is a monotonically decreasing function of $\hat{\theta}$. Therefore, the welfare difference $\Delta W=W^{f}-W^{c}$ is always positive (when $\hat{\theta}>\theta$ ) and an increasing function of $\hat{\theta}$. Therefore, if yardstick inspection has the effect of reducing firms' incentive to report higher inefficiency levels (that is, if yardstick inspection has the effect of reducing the discrepancy between $\theta$ and $\hat{\theta}$ ), it reduces $\Delta W$.

We examine several measures of the effect of yardstick inspection, which are expected to take a negative value if yardstick inspection has the effect of reducing firms' incentive to report higher inefficiency levels. Now, let $R$ be the indicator variable such that $R_{i t}=1$ if distributor $i$ is subject to yardstick inspection in year $\mathrm{t}$ and $R_{i t}=0$ otherwise. Also, let $I$ be the indicator variable such that $I_{i t}=1$ if distributor $i$ applied for a price change and obtained permission in year $\mathrm{t}$ and $I_{i t}=0$ otherwise. That is, when $I_{i t}=0$, a distributor preferred the status quo. Our first measure of the yardstick effect is:

$$
\text { Effect }_{\text {ave }}=E_{i}\left[\text { Diff }_{i}\right]
$$

where $\operatorname{Diff}_{i}=E\left[\Delta W_{i t} \mid R_{i t}=1\right]-E\left[\Delta W_{i t} \mid R_{i t}=0 \& I_{i t}=1\right]$ for each $i$. This is a simple average difference in the welfare disparity with and without yardstick inspection. Next, we examine the effect of simultaneous yardstick inspection:

$$
\text { Effect }_{\text {sim }}=E_{i}\left[\text { Diff }_{\text {sim }, i}\right],
$$

where Diff $f_{s i m, i}=E\left[\Delta W_{i t} \mid R_{i t}=1 \& t=1995\right]-E\left[\Delta W_{i t} \mid R_{i t}=0 \& I_{i t}=1\right]$ for each $i$. This is an 
average difference in the welfare disparity with and without simultaneous yardstick inspection. Next, we examine the effect of individual yardstick inspection:

$$
\text { Effect }_{\text {ind }}=E_{i}\left[\text { Diff }_{\text {ind }, i}\right] \text {, }
$$

where Diff ind, $i=E\left[\Delta W_{i t} \mid R_{i t}=1 \& t \neq 1995\right]-E\left[\Delta W_{i t} \mid R_{i t}=0 \& I_{i t}=1\right]$ for each $i$.

The results are shown in Table 5. We calculate both per-household welfare and total market welfare in each market and calculate the measures of improvement in welfare disparity defined above. The negative values imply that yardstick inspection reduced the adverse selection problem. The first row of Table 5 shows the measure defined in equation (26). We can see that, on average, yardstick inspection improved the per-household welfare disparity. On average, the per-household welfare disparity from the full-information outcome is 26.40 yen smaller under yardstick inspection. The second row shows the measure defined in equation (27). Again, we can see that the per-household welfare disparity is 127.51 yen smaller under yardstick inspection. This implies that the simultaneous yardstick inspection in 1995 was somewhat effective in reducing adverse selection. Measures (26) and (27) calculated with total market welfare, however, show that welfare disparity was widened by yardstick inspection. Total market welfare disparity is 5,604,000 yen larger under yardstick inspection. It is 3,367,000 yen larger under simultaneous yardstick inspection. The result that per-household welfare disparity was improved while total market welfare disparity was not may imply that simultaneous yardstick inspection was effective only for firms in small markets. Because our estimated cost function exhibits scale economies, firms in large markets have a cost advantage. Therefore, our results suggest that the simultaneous yardstick inspection was effective only for firms without a cost advantage in reducing the adverse selection problem: firms with a cost advantage still have incentive to report higher costs even under yardstick inspection, while firms without a cost advantage have a lower incentive to report higher costs. One possible reason for such a phenomenon is that firms are not identical in the yardstick comparison groups. Yardstick grouping may not be appropriate here, and such a grouping may reduce the effect of yardstick inspection.

The measure of the effect of independent yardstick inspections defined in equation (28) shows a different result. On average, it can be seen from the third row that the individual yardstick inspection widened both per-household and total market welfare disparities. The per-household and total market welfare disparities widened, by 647.11 yen and 23,700,000 yen, respectively. This implies that subsequent individual yardstick inspections do not always have the power to 
reduce the adverse selection problem. Why might an individual case not work? One possible reason is that, in such an individual case, the benchmark costs are already known for the firms from the first inspection in 1995. Therefore, our results may give rise to a dynamic concern, similar to the Ratchet effect, because the subsequent inspection cannot be effective for a firm that has learned the relative position of its costs.

Finally, we calculate the additional two measures. The first measure simply looks at the average difference in the welfare disparity before and after the introduction of yardstick inspection, regardless of whether or not the firm is subject to yardstick inspection. Namely:

$$
\text { Effect }_{\text {beforel affer }}=E_{i}\left[\text { Diff }_{\text {beforel affer }, i}\right] \text {, }
$$

where Diff beoferlaffer, $i=E\left[\Delta W_{i t} \mid t \leq 1995\right]-E\left[\Delta W_{i t} \mid t>1995\right]$ for each $i$. The second measure looks at the average difference in the welfare disparity before and after the introduction of yardstick inspection when firms choose the status quo. Namely:

$$
\text { Effect }_{\text {status.quo }}=E_{i}\left[\text { Diff }_{\text {status.quo }, i}\right] \text {, }
$$

where Diff status.quo,$i=E\left[\Delta W_{i t} \mid t \leq 1995 \& I_{i t}=0\right]-E\left[\Delta W_{i t} \mid t>1995 \& I_{i t}=0\right]$ for each $i$. We also calculate these measures by groups. The results are shown in the last 12 rows in Table 5 .

The fifth row in Table 5 (the measure defined in equation (30)) shows that, in general, the welfare disparity from the full-information outcome widened after the introduction of yardstick inspection in 1995. Specifically, the welfare disparity widened by $8,954,000$ yen, while the perhousehold welfare disparity widened by 341.27 yen after 1995. Similar results are observed in all groups except group 12. If we compare the cases where firms kept the status quo (the measure defined in equation (31)), we again find that the welfare disparity widened after the introduction of yardstick inspection. Specifically, as shown in the 11th row, the welfare disparity widened by 9,215,000 yen, while the per-household welfare disparity widened by 385.63 yen after 1995. Again, similar results are observed in all groups except group 12.

Because costs were decreasing during our sample period, keeping the status quo must have led to larger welfare disparity. Moreover, the higher the rate at which costs decrease, the larger the welfare disparity is when a firm keeps the status quo. Therefore, the above results of the larger welfare disparity after 1995 may merely reflect the higher rate of cost decrease in the period after 1995. However, the larger disparity after 1995 is observed even in the groups where the cost decrease rates are not significantly different between the periods before and after the 
introduction of yardstick inspection (see Table 2 for the cost decrease rates). Therefore, our results may imply that the introduction of yardstick inspection reduced firms' incentive to adjust prices.

Why might firms have less incentive to adjust prices under yardstick inspection? This may be explained by firms' collusive behavior. If a firm with decreased costs keeps the status quo, the benchmark cost will be kept high, while if it adjusts prices, the regulator will recognize lower costs and the benchmark cost will be reduced. Therefore, firms may have incentive to collude to keep the status quo.

\section{Conclusion}

This study is aimed at assessing the effect of yardstick inspection in the Japanese retail gas distribution industry. Realizing that yardstick inspection will lead the industry to the fullinformation outcome if it works perfectly to eliminate the adverse selection problem, we infer its effect from the difference between the current and the hypothetical full-information welfare levels.

We estimate a cost function for gas distributors under the assumption of asymmetric information between the regulator and the distributor for the efficient level of labor. It is assumed that the regulator does not observe either the inefficiency level or the effort level of each distributor. As the existing regulation has an incentive mechanism to induce the distributor's effort, the distributor is assumed to maximize the utility with respect to the effort level. Therefore, the effort level can be solved as a function of the parameters. Using distributional assumption regarding the inefficiency level, maximum likelihood estimation is conducted to estimate the parameters, except the inefficiency level, and then, the inefficiency level is recovered by the method in Jondrow et al. (1982). It was shown that most distributors were quite efficient. Having obtained all the parameters, the welfare levels under the current and the full-information situations are calculated. Our results indicate that the welfare difference between the current and the full-information outcomes is somewhat reduced by yardstick inspection on average, implying that the inspection reduced firms' incentive to report higher costs.

Yardstick inspection was introduced in 1995. In that year, all the firms were required to report their costs for comparison. Since then, only the firms that apply for a price change are subject to 
inspection and the most recent costs of the other firms (which do not apply for a price rise and do not report costs) are used as the benchmark. Our results show that the initial inspection in 1995 reduced the welfare discrepancy, while the later individual cases did not. This may give rise to a dynamic concern, similar to the Ratchet effect, such that subsequent inspection cannot be effective for a firm that has learned the relative position of its cost. Furthermore, the inspection seems to have discouraged firms from changing prices. Our results from this study suggest that a better form of regulation, which takes into account firms' dynamic incentive, should be considered. 


\section{Appendix I}

We show that if the slope of the inverse demand curve is smaller than the average cost curve, reporting a higher inefficiency level $\hat{\theta}$ leads to a lower regulated price and higher output.

As in equation (19), the regulator set the regulated price so that :

$$
\begin{aligned}
P\left(Y^{r}\right) Y^{r} & =C\left(Y^{r}, K, \omega, e^{*}\left(Y^{r}, K, \omega, \hat{\theta} \mid \beta\right), \hat{\theta} \mid \beta\right)+s B \\
& =\beta_{0} \exp \left[\beta_{L}\left(\hat{\theta}-e^{*}\left(Y^{r}, K, \omega, \hat{\theta} \mid \beta\right)\right)\right] \omega_{L}^{\beta_{L}} \omega_{G}^{\beta_{G}} \omega_{M}{ }^{\beta_{M}} K^{\beta_{K}} Y^{r \beta_{Y}}+s B
\end{aligned}
$$

where

$e^{*}\left(Y^{r}, K, \omega, \hat{\theta} \mid \beta\right)=\frac{\beta_{L} \hat{\theta}+\ln \beta_{L} \beta_{0}-\ln \alpha+\beta_{L} \ln \omega_{L}+\beta_{G} \ln \omega_{G}+\beta_{M} \ln \omega_{M}+\beta_{K} \ln K+\beta_{Y} \ln Y^{r}}{\alpha+\beta_{L}}$.

By totally differentiating the above equation, we obtain:

$$
\frac{d Y}{d \hat{\theta}}=\frac{\frac{\alpha}{\alpha+\beta_{L}} \beta_{L} C}{P^{\prime}(Y) Y+P(Y)-\beta_{Y} \frac{C}{Y}+\frac{\beta_{L}}{\alpha+\beta_{L}} \beta_{y} \frac{C}{Y}}
$$

Therefore, $\frac{d Y}{d \hat{\theta}}<0$ if

$$
P^{\prime}(Y)<-\frac{C+s B}{Y^{2}}+\beta_{y} \frac{C}{Y^{2}}-\frac{\beta_{L}}{\alpha+\beta_{L}} \beta_{y} \frac{C}{Y^{2}}
$$

The left side of the above inequality is the slope of the inverse demand curve and the right side is the slope of the average cost curve. Therefore, if the slope of the inverse demand curve is smaller than the average cost curve, reporting a higher inefficiency level $\hat{\theta}$ leads to a lower regulated price and higher output.

We confirmed that, with our estimated parameter values, inequality (30) indeed holds in all the markets of our observation for a broad range of output level. ${ }^{17}$

\section{Appendix B}

In this appendix, we show that current welfare $W^{c}(\theta, \hat{\theta})$ is a monotonically decreasing function of $\hat{\theta}$.

\footnotetext{
${ }^{17}$ Specifically, we have checked the range from the half to the double of the current output level.
} 
Differentiating equation (24) by $\hat{\theta}$, we obtain the following:

$$
\frac{d W^{c}(\theta, \hat{\theta})}{d \hat{\theta}}=\left[P(Y)-\beta_{y} C\left(1-\frac{\beta_{L}}{\alpha+\beta_{L}}\right) \frac{1}{Y}-\alpha \exp \left(\alpha e^{*}\right) \frac{\beta_{Y}}{\alpha+\beta_{L}} \frac{1}{Y}\right] \frac{d Y}{d \hat{\theta}}
$$

But we know, from Appendix A, that $\frac{d Y}{d \hat{\theta}}<0$. Therefore, $\frac{d W^{c}(\theta, \hat{\theta})}{d \hat{\theta}}<0$ if

$$
\Phi(Y) \equiv\left[P(Y)-\beta_{y} C\left(1-\frac{\beta_{L}}{\alpha+\beta_{L}}\right) \frac{1}{Y}-\alpha \exp \left(\alpha e^{*}\right) \frac{\beta_{Y}}{\alpha+\beta_{L}} \frac{1}{Y}\right]>0
$$

The value of the left hand side of the above inequality $\Phi(Y)$ depends on the level of $Y$. With our parameter values, we graphically confirmed that $\Phi(Y)$ is always positive for all $Y$ such that $Y<Y(\theta) \cdot{ }^{18}$ That is, $\frac{d W(\hat{\theta})}{d \hat{\theta}}<0$ for all $Y$ such that $Y<Y(\theta)$ : welfare is monotonically decreasing in $\hat{\theta}$ for the level of $Y$ such that $Y \leq Y(\theta) .{ }^{19}$

\footnotetext{
${ }^{18}$ The graphs are available from the author upon request.

${ }^{19}$ Because Appendix A shows that reporting higher $\hat{\theta}$ decreases $Y$, we only need to consider the range of Y such that $Y<Y(\theta)$.
} 


\section{References}

Antonioli, B., Filippini, M., 2001. The Use of a variable cost function in the regulation of the Italian water industry. Utilities Policy 10, 181-187.

Auriol, E., Laffont, J.J., 1992. Regulation by duopoly. Journal of Economics and Management Strategy. 1, 507-533.

Baron, D.P., Myerson, R.B., 1982. Regulating a monopolist with unknown costs. Econometrica 50, 911-930.

Chong, E., 2003. Yardstick competition vs. individual incentive regulation: What has the theoretical literature to say? mimeo. ADIS and ATOM.

Cornwell, C., Schmidt, P., Sickles, R.C., 1990. Production frontiers with cross-sectional and time-series variation in efficiency levels. Journal of Econometrics 46, 185-200.

Dalen, D.M., Gómez-Lobo, A., 2003. Yardstick on the road: Regulatory contracts and cost efficiency in the Norwegian bus industry. Transportation 30, 371-386.

Farsi, M., Filippini, M., 2004. Regulation and measuring cost-efficiency with panel data models: Application to electricity distribution utilities. Review of Industrial Organization 25, 1-19.

Gagnepain, P., Ivaldi, M., 2002. Incentive regulatory policies: the case of public transit systems in France. RAND Journal of Economics 33, 605-629.

Jondrow, J., Konox Lovell, C.A., Materov, I.S., Schmidt, P., 1982. On the estimation of technical inefficiency in the stochastic frontier production function model. Journal of Econometrics 19, 233-238.

Laffont, J.J., Tirole, J., 1986. Using cost observation to regulate firms. Journal of Political Economy 94, 614-641.

Lewis, T.R., Sappington, D.E.M., Regulating a monopolist with unknown demand. American Economic Review 78, 986-998.

Potters, J., Rockenbach, B., Sadrieh,, A., van Damme, E., 2004. Collusion under yardstick competition: an experimental study. International Journal of Industrial Organization 22, 1017-1038.

Shleifer, A., 1985. A Theory of yardstick competition. RAND Journal of Economics 16, 319327.

Tangerås, T.P., 2002. Collusion-proof yardstick competition. Journal of Public Economics 83, 231-254.

Vuong, Q., 1989. Likelihood ratio tests for model selection and non-nested hypotheses. Econometrica 57, 307-334. 
Wolak, F.A., 1994. An econometric analysis of the asymmetric information, regulator-utility interaction. Annales d'Economie et de Statistique 34, 13-69.

Yatchew, A., 2001. Incentive regulation of distributing utilities using yardstick competition. Electricity Journal 14, 56-60. 
Table 1: Summary statistics

\begin{tabular}{|c|c|c|c|c|c|c|c|c|c|c|}
\hline $\begin{array}{c}\text { Production } \\
\text { type }\end{array}$ & & $\begin{array}{r}\text { Output } \\
\left(\mathrm{m}^{3}\right) \\
\end{array}$ & $\begin{array}{r}\text { Total cost } \\
\text { (1000 yen) }\end{array}$ & $\begin{array}{r}\text { Labor price } \\
\text { (1000 yen })\end{array}$ & $\begin{array}{r}\text { Material price } \\
(1000 \text { yen }) \\
\end{array}$ & $\begin{array}{r}\text { Gas price } \\
\left(1000 \text { yen } / m^{3}\right) \\
\end{array}$ & $\begin{array}{r}\text { Capital } \\
(\mathrm{m}) \\
\end{array}$ & $\begin{array}{r}\text { Consumer price } \\
\left(\text { yen } / \mathrm{m}^{3}\right)\end{array}$ & $\begin{array}{r}\text { Capital cost } \\
\text { (1000 yen) }\end{array}$ & $\begin{array}{l}\text { Number } \\
\text { of firms }\end{array}$ \\
\hline \multirow[t]{2}{*}{1} & Mean & 9129486 & 673577 & 6869 & 14.825 & 0.0443 & 249432 & 112.414 & 136842 & 59 \\
\hline & s.d. & 14400000 & 949049 & 1433 & 10.069 & 0.0055 & 262417 & 26.263 & 96701 & \\
\hline \multirow[t]{2}{*}{2} & Mean & 16400000 & 1681445 & 6990 & 20.114 & 0.0347 & 494968 & 152.705 & 1051975 & 21 \\
\hline & s.d. & 44000000 & 4198267 & 1424 & 9.413 & 0.0067 & 1112475 & 19.472 & 383928 & \\
\hline \multirow[t]{2}{*}{3} & Mean & 15400000 & 1892904 & 7053 & 18.645 & 0.0355 & 848017 & 170.820 & 387286 & 3 \\
\hline & s.d. & 13700000 & 1568506 & 1457 & 8.999 & 0.0065 & 615647 & 12.212 & 446240 & \\
\hline \multirow[t]{2}{*}{ Total } & Mean & 11100000 & 966965 & 6906 & 16.248 & 0.0418 & 334483 & 124.608 & 180327 & 76 \\
\hline & s.d. & 25000000 & 2262789 & 1432 & 10.125 & 0.0072 & 616029 & 31.346 & 545884 & \\
\hline
\end{tabular}

Note: Production type 1 includes those without vaporization systems or reformers. Type 2 includes those with vaporization systems. Type 3 includes those with reformers.

The total number of firms is larger than the sum of the number of firms in each production type because some distributors switched their production type during the sample period. 
Table 2: Cost and Price before and after the introduction of yardstick

\begin{tabular}{|c|c|c|c|c|c|c|c|c|c|c|}
\hline \multirow[b]{2}{*}{ Group } & \multirow[b]{2}{*}{ Period } & \multicolumn{3}{|c|}{$\begin{array}{c}\text { Average operating cost } \\
\text { (yen) }\end{array}$} & \multicolumn{3}{|c|}{$\begin{array}{l}\text { Price } \\
\text { (yen) }\end{array}$} & \multicolumn{3}{|c|}{$\begin{array}{c}\text { Annual growth rate of } \\
\text { average operating cost } \\
(\%)\end{array}$} \\
\hline & & Before & After & & Before & After & & Before & After & \\
\hline \multirow[t]{2}{*}{ Group 12} & Mean & 129.65 & 120.57 & $* * *$ & 152.65 & 151.39 & & -0.780 & -0.284 & \\
\hline & S.D. & 23.83 & 20.56 & & 24.71 & 25.95 & & 0.851 & 0.896 & \\
\hline \multirow[t]{2}{*}{ Group 13} & Mean & 82.05 & 73.02 & $* * *$ & 105.87 & 101.77 & $* * *$ & -0.191 & -1.591 & \\
\hline & S.D. & 26.31 & 14.89 & $* * *$ & 16.73 & 14.54 & $*$ & 0.781 & 0.523 & $*$ \\
\hline \multirow[t]{2}{*}{ Group 14} & Mean & 82.96 & 77.86 & $* * *$ & 101.66 & 97.99 & & 0.467 & -1.239 & $*$ \\
\hline & S.D. & 12.00 & 14.48 & $*$ & 16.22 & 13.95 & & 0.585 & 0.453 & \\
\hline \multirow[t]{2}{*}{ Group 15} & Mean & 86.81 & 83.18 & & 123.00 & 124.05 & & -2.453 & -1.951 & \\
\hline & S.D. & 6.16 & 24.57 & $* * *$ & 5.22 & 20.37 & $* * *$ & 1.084 & 1.714 & $*$ \\
\hline \multirow[t]{2}{*}{ Total } & Mean & 92.21 & 82.24 & $* * *$ & 115.12 & 109.69 & $* * *$ & -0.244 & -1.310 & $*$ \\
\hline & S.D. & 29.55 & 23.47 & $* * *$ & 26.61 & 25.34 & & 0.466 & 0.346 & \\
\hline
\end{tabular}

Note: The differences of means and standard deviations are tested by T-test and F-test, respectively. Stars refer to the significance. $*=$ significant at the $10 \%$ level; $* *=$ significant at the $5 \%$ level; and $* * *=$ significant at the $1 \%$ level. 
Table 3: Parameter estimates of the cost function

\begin{tabular}{|c|c|c|c|c|}
\hline \multirow{2}{*}{$\begin{array}{l}\text { Type of model } \\
\text { parameter }\end{array}$} & \multicolumn{2}{|c|}{ Asymmetric information case } & \multicolumn{2}{|c|}{ Standard case } \\
\hline & Estimate & Standard error & Estimate & Standard error \\
\hline$\alpha$ & 45.313 & 31.5122 & & \\
\hline$\beta_{0}$ & 0.0722 & 0.0085 & & \\
\hline$\beta_{L}$ & 0.2497 & 0.0187 & 0.1000 & 0.0287 \\
\hline$\beta_{G}$ & 0.4421 & 0.0205 & 0.6580 & 0.0308 \\
\hline$\beta_{K}$ & 0.1676 & 0.0098 & 0.1371 & 0.0148 \\
\hline$\beta_{Y}$ & 0.7708 & 0.0077 & 0.7643 & 0.0117 \\
\hline$\beta_{t}$ & -0.0005 & 0.0155 & -0.0005 & 0.0233 \\
\hline$\mu$ & 0.8445 & 0.4607 & & \\
\hline$v$ & 1.9648 & 0.2385 & & \\
\hline$\sigma_{c}$ & 0.1624 & 0.0922 & 0.1770 & 0.1025 \\
\hline Log likelihood & \multirow{2}{*}{\multicolumn{2}{|c|}{$\begin{array}{c}251.2 \\
754\end{array}$}} & \multirow{2}{*}{\multicolumn{2}{|c|}{$\begin{array}{c}236.0 \\
754\end{array}$}} \\
\hline \# of observations & & & & \\
\hline
\end{tabular}


Table 4: Demand Estimation

\begin{tabular}{lcr}
\hline \hline Log output & Coefficient & \multicolumn{2}{c}{ Standard error } \\
\hline Log price & -0.275 & 0.143 \\
Constant & 16.005 & 0.708 \\
Fixed effect & \multicolumn{2}{c}{ Yes } \\
Year dummy & \multicolumn{2}{c}{ Yes } \\
\hline Number of Observation & 1046 \\
Adjusted R-squared & 0.9696 \\
F-test (91, 954) & 367.61 \\
\hline
\end{tabular}


Table 5: Welfare disparity between current and full information outcome:

Difference before and after the introduction of Yardstick

\begin{tabular}{|c|c|c|c|c|}
\hline \multirow{2}{*}{$\frac{\text { Measure }}{\text { Effect }_{\text {ave }}}$} & \multicolumn{2}{|c|}{$\begin{array}{l}\text { Per household } \\
\text { (yen) }\end{array}$} & \multicolumn{2}{|c|}{$\begin{array}{l}\text { Whole market } \\
\text { (thousand yen) }\end{array}$} \\
\hline & -26.40 & $(62.02)$ & 5604 & (682) \\
\hline Effect $_{\text {sim }}$ & -127.51 & $(62.16)$ & 3363 & (372) \\
\hline Effect $_{\text {ind }}$ & 647.11 & (143.18) & 23700 & (2142) \\
\hline \multicolumn{5}{|l|}{ Effect $_{\text {before, after }}$} \\
\hline Total & 341.27 & (42.24) & 8954 & (285) \\
\hline Group 12 & -19.47 & $(206.65)$ & 297 & (585) \\
\hline Group 13 & 448.35 & (26.46) & 5183 & (197) \\
\hline Group 14 & 162.08 & (48.95) & 8857 & (490) \\
\hline Group 15 & 1504.50 & $(76.82)$ & 99300 & (5236) \\
\hline \multicolumn{5}{|l|}{ Effect $_{\text {status.quo }}$} \\
\hline Total & 385.63 & (48.97) & 9215 & (309) \\
\hline Group 12 & -107.98 & $(245.21)$ & -664 & (667) \\
\hline Group 13 & 542.25 & (28.48) & 5664 & (206) \\
\hline Group 14 & 197.37 & (47.10) & 9701 & (519) \\
\hline Group 15 & 1527.86 & (83.12) & 98900 & (5698) \\
\hline
\end{tabular}

Note: Negative value implies reduction in incentive to report higher cost. Inside the parentheses are standard errors. 
Figure 1: Grouping for yardstick inspection

Private Gas Suppliers

\begin{tabular}{|c|c|c|c|c|}
\hline & $\begin{array}{l}\text { Number of } \\
\text { households in } \\
\text { market: more than } \\
150,000\end{array}$ & $\begin{array}{l}\text { From wholesale } \\
\text { supplier (suppliers } \\
\text { without vaporization } \\
\text { system) }\end{array}$ & $\begin{array}{l}\text { LNG satellite, } \\
\text { LPG air (with } \\
\text { only vaporization } \\
\text { system) }\end{array}$ & $\begin{array}{l}\text { Petroleum } \\
\text { (suppliers with } \\
\text { reformer) }\end{array}$ \\
\hline $\begin{array}{c}\text { Hokkaido } \\
\text { Tohoku }\end{array}$ & \multirow{4}{*}{ Group 1} & \multicolumn{2}{|c|}{ Group 2} & Group 3 \\
\hline Kanto & & Groups 4 \& 5 & Groups $6 \& 7$ & \\
\hline $\begin{array}{c}\text { Chubu } \\
\text { Hokuriku } \\
\text { Kinki }\end{array}$ & & \multicolumn{2}{|c|}{ Group 9} & Group 8 \\
\hline $\begin{array}{c}\text { Chugoku } \\
\text { Shikoku } \\
\text { Kyushu } \\
\text { Okinawa }\end{array}$ & & \multicolumn{2}{|c|}{ Group 10} & Group 11 \\
\hline
\end{tabular}

Public Gas Suppliers

\begin{tabular}{|c|l|l|l|}
\hline & $\begin{array}{l}\text { From wholesale } \\
\text { supplier (suppliers } \\
\text { without } \\
\text { vaporization } \\
\text { system) }\end{array}$ & $\begin{array}{l}\text { LNG satellite, LPG } \\
\text { air (with only } \\
\text { vaporization system) }\end{array}$ & $\begin{array}{l}\text { Petroleum } \\
\text { (suppliers with } \\
\text { reformer) }\end{array}$ \\
\hline $\begin{array}{c}\text { Hokkaido } \\
\text { Tohoku }\end{array}$ & \multicolumn{2}{|c|}{ Group 12 } & \\
\hline Kanto & Groups 13 \& 14 & \multirow{2}{*}{ Group 16 } \\
\hline $\begin{array}{c}\text { Chubu } \\
\text { Hokuriku } \\
\text { Kinki }\end{array}$ & \multicolumn{2}{|}{} \\
\cline { 1 - 2 } $\begin{array}{c}\text { Chugoku } \\
\text { Shikoku } \\
\text { Kyushu } \\
\text { Okinawa }\end{array}$ & Group 15 & \\
\hline
\end{tabular}

* The first column in each table shows the names of districts. 
Figure 2: Recent average unit price of public firms

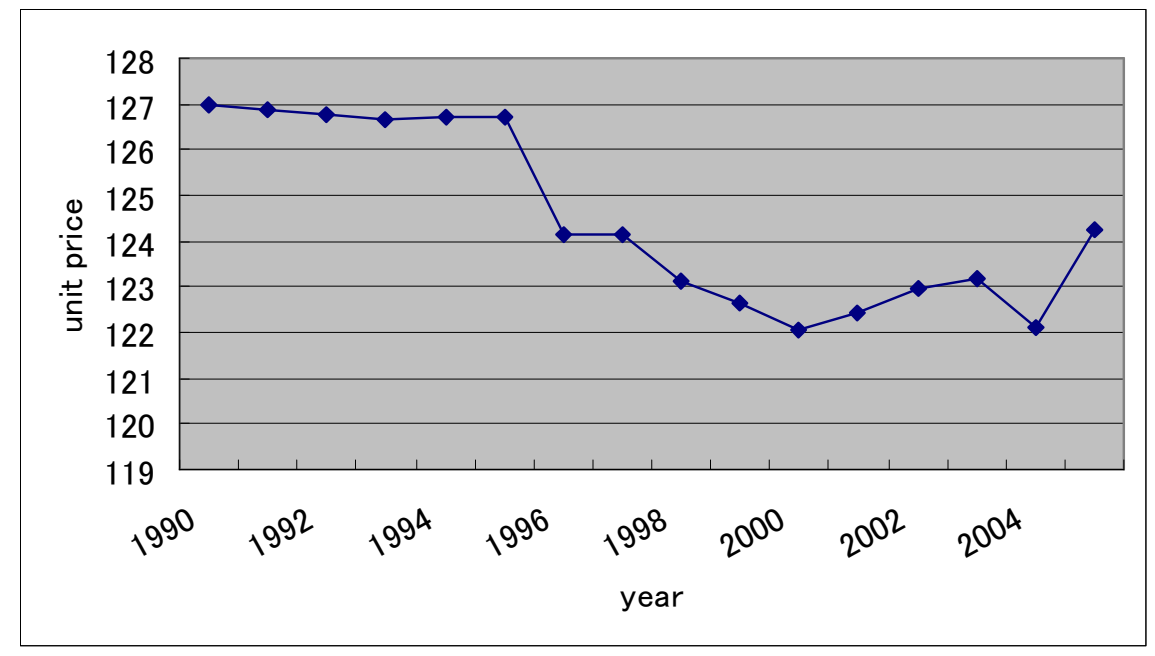


Figure 3: Inefficiency parameter and cost distortion

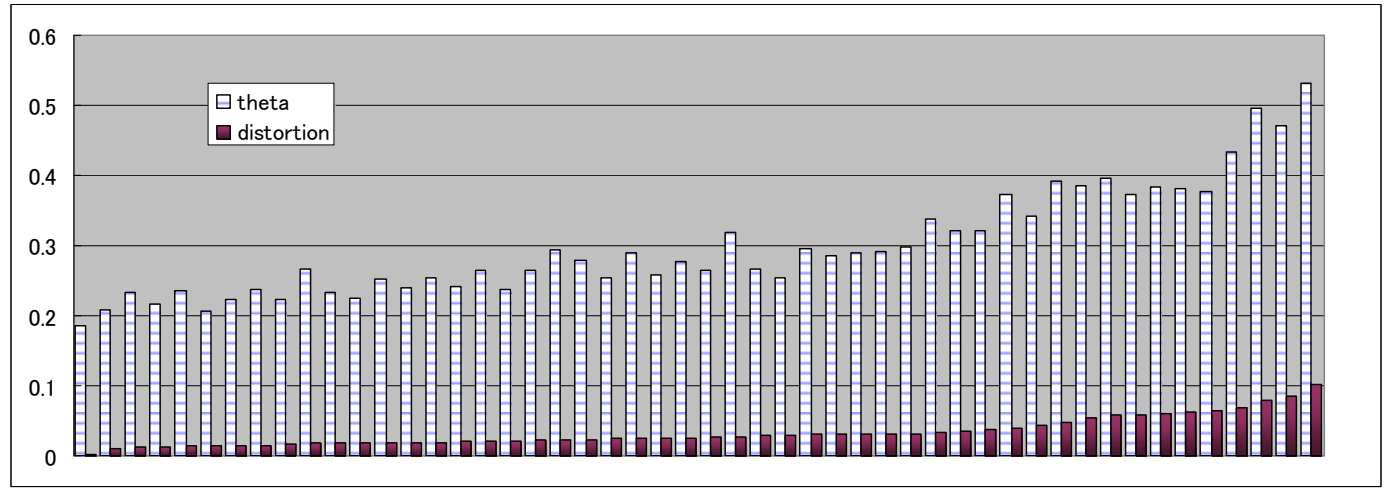


Figure 4: Reported and True Inefficiency Levels and Price and Output:

With Inelastic Demand

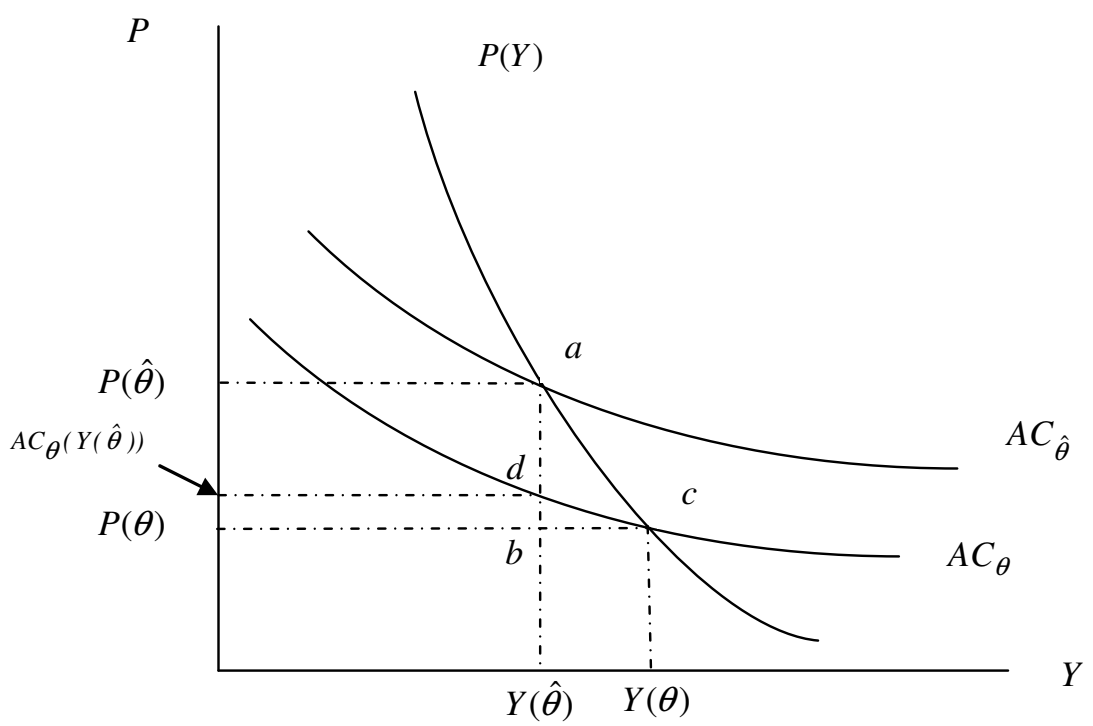

